\title{
Torulopsis glabrata and Candida albicans in female genital infections in the Sudan*
}

\author{
EL-FADIL E OMER, + S A GUMAA, + H A EL-NAEEM, $\neq$ AND M HAG ALI§ \\ From the Department of + Medical Microbiology and $\ddagger$ Obstetrics and Gynaecology, Faculty of Medicine, \\ Khartoum, and the §Sudan Medical Research Council, Khartoum, Sudan
}

SUMMARY Four hundred and seventy Sudanese women with vaginal discharge were investigated for yeast-like fungi. High vaginal specimens were cultured and isolates fully identified according to standard mycological techniques. All patients were married and some were pregnant.

Of 138 yeast-like fungi identified, Torulopsis glabrata $(34 \cdot 1 \%)$ was the commonest followed by Candida albicans (25.4\%) and Candida krusei (14.5\%). Differing social and economic factors may be reponsible for the higher prevalence of $T$ glabrata in the Sudan. Although its pathogenicity is not well established, its association with vulvovaginitis should not be overlooked.

\section{Introduction}

Fungal infection of the vagina was recognised as a pathological condition in the nineteenth century. ${ }^{1}$ In the Sudan studies have been carried out to determine the importance and incidence of mycotic infections in men $^{2}$ and women. ${ }^{34}$ Mycotic agents may be actual or potential pathogens in the genital tract, and many workers have studied their distribution in various population groups, often with conflicting results. Different species of the genera Candida and Torulopsis have been isolated and correlated with the pathological condition. ${ }^{5}$

The aim of this study was to determine the prevalence of yeasts and yeast-like fungi in the vagina of Sudanese women presenting with vaginal discharge.

\section{Patients and methods}

The patients investigated were adult women presenting with vaginal discharge to the sexually transmitted diseases clinic at Samir Health Centre, Khartoum. Some of the patients were diagnosed as having acute vaginitis and others pelvic inflammatory disease. None of the patients was diabetic or unmarried. Although some were pregnant, many were using oral contraceptives.

*Paper read at the 30th General Assembly of the International Union against the Venereal Diseases and Treponematoses, East Berlin, June 1980

Address for reprints: Dr El-Fadil E Omer, Department of Medical Microbiology, Faculty of Medicine, P O Box 102, Khartoum, Sudan

\section{CULTURE TECHNIQUE}

Single vaginal specimens were collected using a Cusco's bivalve speculum. ${ }^{4}$ Material from the vaginal wall was collected with a sterile wire loop and inoculated directly on to glucose-peptone agar (Sabouraud's medium) with $0.05 \%$ chloramphenicol and transported to the laboratory within 30 minutes. Cultures were incubated at $37^{\circ} \mathrm{C}$ for $24-48$ hours.

\section{IDENTIFICATION OF YEASTS}

Films were made from all cultures showing growth, stained by Jensen's modification of Gram's stain, and examined for yeasts. Further identification was carried out on all the isolated yeasts by germ-tube production in human serum and chlamydospore formation on corn-meal agar. Sugar fermentation (zymogram) and sugar assimilation (auxanogram) of glucose, maltose, sucrose, lactose, galactose, trehalose, raffinose, and cellobiose were also performed, as well as nitrogen assimilation of potassium nitrate and asparagin. ${ }^{3}$

Interpretation of results was carried out according to the method of Emmons et al. ${ }^{6}$

\section{Results}

Of 470 specimens investigated, yeast-like organisms were grown from $138(29 \cdot 7 \%)$. The species of yeasts isolated are shown in the table.

\section{CANDIDA SPECIES}

Candida species ( 87 isolates) were the predominant organisms in all specimens investigated $(18.5 \%)$ and in all cultures showing growth $(63 \%)$. Candida albicans was the commonest species of Candida 
TABLE Types of yeasts isolated

\begin{tabular}{lcc}
\hline Type of yeast & No isolated & $\%$ of total \\
\hline Candida albicans & 35 & $7 \cdot 4$ \\
Candida krusei & 20 & $4 \cdot 3$ \\
Candida parapsilosis & 7 & $1 \cdot 5$ \\
Candida stellatoidea & 6 & $1 \cdot 3$ \\
Candida parakrusei & 4 & $0 \cdot 9$ \\
Candida guillermondii & 4 & $0 \cdot 9$ \\
Candida pseudotropicalis & 2 & $0 \cdot 4$ \\
Candida tropicalis & 1 & $0 \cdot 2$ \\
Candida species (unidentified) & 8 & $1 \cdot 7$ \\
Torulopsis glabrata & 47 & $10 \cdot 0$ \\
Torulopsis candida & 2 & $0 \cdot 4$ \\
Trichosporon cutaneum & 1 & $0 \cdot 2$ \\
Rhodotorula rubra & 1 & $0 \cdot 2$ \\
Contaminated cultures & 31 & $6 \cdot 6$ \\
No growth & 301 & $64 \cdot 0$ \\
Total No of specimens & 470 & $100 \cdot 0$ \\
\hline
\end{tabular}

isolated followed by $C$ krusei. Their isolation rates in relation to the total Candida species identified were $40 \cdot 2 \%$ and $23 \%$ respectively.

\section{TORULOPSIS SPECIES}

Torulopsis species (49 isolates) occurred next in frequency to Candida species in all specimens $(10.4 \%)$ and in all isolates showing growth $(35.6 \%)$ Torulopsis glabrata was the most frequently isolated species in this genus and was isolated more often $(10 \%)$ than $C$ albicans $(7 \cdot 4 \%)$. Of the total number of yeasts isolated (138), $T$ glabrata was the commonest $(34 \cdot 1 \%)$, then $C$ albicans $(25 \cdot 4 \%)$ and $C$ krusei $(14 \cdot 5 \%)$.

\section{Discussion}

Yeasts and yeast-like fungi are widely distributed in nature and in the Sudan. In a study to evaluate the importance of yeasts isolated from urine specimens of female Sudanese patients, Gumaa ${ }^{3}$ found the commonest was $C$ kruse $i$ followed by $C$ albicans and $T$ glabrata. $\mathrm{Omer}^{4}$ studied species of Candida isolated from vaginal discharge of Sudanese women in Khartoum and reported that $29.2 \%$ harboured the organism; $C$ albicans represented $20.5 \%$ of the Candida species isolated.

$T$ glabrata may rarely cause vaginitis and is frequently isolated from vaginal swabs sent for the diagnosis of vaginitis. ${ }^{1}$ It can produce a clinical and symptomatic picture similar to that of the genus Candida. ${ }^{5}$ Most of the yeast-like fungi are secondary pathogens in patients with a primary disease. $T$ glabrata has a low degree of virulence, but it can sometimes cause a secondary infection. ${ }^{6}$

It is now widely accepted that $C$ albicans is not part of the normal flora of the vagina and that its $\frac{\mathbb{Q}}{\mathrm{D}}$ presence indicates morbidity. ${ }^{1}$

In England $C$ albicans was found to be the commonest infectious agent isolated from female $\overrightarrow{\vec{s}}$ patients attending clinics for the diagnosis of sexuallyo transmitted diseases. $C$ krusei, $C$ stellatoidea, and $C$ 듬 tropicalis were also associated with vaginitis in some $\overline{\bar{n}}$ other countries. ${ }^{5}$ In a study carried out at Queen $\widehat{\mathbb{Q}}$ Charlotte's Hospital, London, $C$ albicans comprised $94 \%$ of all isolates of yeasts from women with ${ }^{\text {cs }}$ mycotic vulvovaginitis and $T$ glabrata accounted for $\vec{\circ}$ 3.5\%. ${ }^{1}$ Morton and Rashid ${ }^{7}$ quoted that $C$ albicans $\overrightarrow{.}$ is responsible for $80-95 \%$ of cases of vulvovaginitis $\omega$ and $T$ glabrata for $3-16 \%$. It was concluded thato there is a geographical variation in the species of $r$ Candida producing genital candidosis. This is not ${ }_{\omega}^{-}$ unexpected in view of the importance of diet and climatic and host factors. ${ }^{5}$ Furthermore, social and economic factors may affect the geographical distri-음 bution of yeasts. ${ }^{6}$

In our study $T$ glabrata was more prevalent than $C_{C}$ albicans (table). This result differs from other reports and may be explained by the different environmental $\vec{A}$ conditions and habits of the Sudanese people $\infty$ compared with those of other societies. Although the ${ }^{-}$ pathogenicity of $T$ glabrata is not as well established as that of $C$ albicans, its association with vulvovaginitis should not be overlooked. Further studieso are required in similar countries to confirm theseô๊ findings.

Our thanks are due to the medical of ficer-in-charge, $\stackrel{3}{3}$ Samir Health Centre, Khartoum, for his support and $\bar{F}$ co-operation. The assistance of technicians in the? mycology laboratory of the Faculty of Medicine, 0 Khartoum, is gratefully acknowledged.

\section{References}

1. Hurley R. Candidal vaginitis. Proc $R$ Soc Med 1977; 70: supplo 4:1-2.

2. Taha OMA, Hag Ali M, Omer EE, Ahmed MA, Abbaro SA, $\mathbb{D}$ Study of STDs in patients attending venereal disease clinics inㅡㅡ. Khartoum, Sudan. Br J Vener Dis 1979;55:313-5.

3. Gumaa SA. The significance of yeasts in urine specimens from female Sudanese patients. East Afr Med J 1979;56:293-5.

4. Omer EE. Candidosis in women presenting with vaginal dis- $N$ charge in Khartoum. Sudan Medical Journal 1977;15:17-22. N

5. Harris JRW. Introduction, epidemiology and social aspects of candidiasis. In: Morton RS, Harris JRW, eds. Recento Advances in Sexually Transmitted Diseases. Edinburgh, London and New York: Churchill Livingstone, 1975:231-4.

6. Emmons CW, Binford CH, Utz JP, Kwon-Chung KJ. Medica $\bar{D}$ Mycology. 3rd ed. Philadelphia: Lea and Febiger, 1977:488. \&

7. Morton RS, Rashid S. Candidal vaginitis: natural history, predisposing factors and prevention. Proc $R$ Soc Med 1977; 70 suppl 4: 3-6. 